\title{
THE DAY IN COURT: LEGAL EDUCATION AS SOCIOLEGAL RESEARCH PRACTICE IN THE FORM OF AN ETHNOGRAPHIC STUDY
}

\author{
KLAUS A ZIEGERT*
}

\section{SOCIOLOGY OF LAW AND LEGAL EDUCATION}

According to Eugen Ehrlich, one of the acknowledged predecessors of modern sociology of law at the turn of this century, the most important virtue of the accomplished lawyer was to be a "sharp eye for the essence of the societal processes in the present, a high sensitivity for the needs of today and a relationship to the

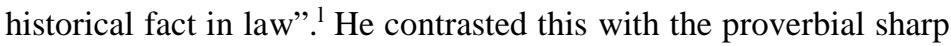
wit of a lawyer which he considered to be "one of the most fruitless of the gifts of human intellect". ${ }^{2}$ There cannot be any doubt that Ehrlich had a lawyer in mind who was an expert on context rather than on mindless detail. However, the target of Ehrlich's attack was not lawyers as such, but the ossified institutions which produced them. Sociology of law as a new, and as Ehrlich postulated, scientific approach to legal practice had to change those institutions and their kind of legal education. ${ }^{3}$

Today, nearly at the end of the century which saw the unfolding of sociology of law, we can confidently say that neither the lawyers nor the institutions which produce them have changed all that much. As far as there was change in legal education, it owes very little to sociology of law and a lot to how legal education has always operated. ${ }^{4}$ There have been the perennial curriculum reviews and reforms; new courses and new legally relevant assessments of context have been introduced in law schools; new 
confrontations with different theory and critical analysis have entered the old scene. But it is highly doubtful whether all of this has had the fundamental emancipative effect which Ehrlich had in mind. And it remains doubtful, and certainly institutionally irrelevant, why lawyers would need a sharp eye for the essence of societal process, once one goes beyond the rhetoric of curriculum reform.

A sociological observation of legal education leads to the rather trivial conclusion that legal education does not change much as long as legal systems do not change much and that legal systems do not change much as long as they are designed to operate legal decisions normatively. ${ }^{5}$ This conclusion is less trivial for those who, like Ehrlich, want to overcome the extremely powerful definition of legal education by legal practice, a practice which cannot be explained by legal theory other than by reference to further legal practice. For the purpose of legal theory, law is defined as what statutes, judges and administrators say. Those academic lawyers who feel the limitations of reproducing legal education as a theory of legal practice are caught in a dilemma. They can observe and teach law from a position outside legal practice and legal education, and with reference to social or any other scientific theory. However, these references are of little consequence to legal practice and they tend to become marginalised in legal education. Alternatively, they can observe and teach law from a position within the legal system and with reference to legal theory and legal practice. However, these references are of little use to law students. They do not explain the operation of law better than students get to know by internalising legal work practices while passing through law school. A result of the law teachers dilemma is that the use of any other than legal theory — from the critical application of social theory by the European Freirechtsschule and the American or Scandinavian Realists in the past to the application of anti-institutional theory by the Critical Legal Studies movement in the present - is either carved up in legally relevant titbits or is dogmatically purified for consumption in law school classes. ${ }^{6}$ In neither case do social sciences, and least of all sociology of law, perform a particularly emancipative job. It is much more likely, in each case, that they are subsumed under the requirements of legal practice to be practical, to give immediate 
answers and not to ask too many awkward questions.

One way out of the dilemma of law teachers and faculties is to conduct legal education as legal studies rather than as a theory of legal practice. This approach posits that, in order to understand and learn the operation of law, it is not enough to internalise legal practice. Law must be seen and studied as a social practice. As such, law is part of social organisation at large, its historical processes and its evolutionary differentiation. For the legal studies approach to succeed, it is necessary to leave sociological theory intact even if used in the jurisprudential domain. Further, the legal studies approach posits - and this takes us back to Eugen Ehrlich - that the application of sociological theory is a "hands on" experience for the law student. This means that, learning law is experienced as a sociological observation of the social practice of law which can be conducted by the students themselves just as much as dogmatic expertise is trained successfully only where the law student learns to argue successfully by imitating legal practice. ${ }^{7}$

This is an attempt to achieve more than simply placing the sociological or sociolegal course alongside others ready for rote learning; that is, a course which just equips the law student with the dogmatic wisdom of the history of ideas of sociology of law, a hotch-potch of possible theoretical approaches, a collection of sociological "buzzwords", a knowledge of the literature of major sociolegal studies and, at best, a hit-list of social science research techniques. Instead, the integrity of constructing sociological theory can also be preserved in a legal education environment if the use of sociological theory is practised. Practice demonstrates to law students that sociological theory is as much or as little the final word on the social reality of law as a statute or a judicial decision is the final conclusion on the legal reality of law. Law students will learn to understand that the use of sociological theory is only meaningful if it ties in with (practical) social science research observations, and that research can only be meaningful if it is guided by theory. Also lawyers, as much or as little as sociologists, do not develop sharp eye for social process just by looking into books. In sum, legal education - if it wants to be committed to organising practical sociological knowledge for lawyers as the legal studies approach suggests it should be - should not be allowed to have sociology of law taught as legal doctrine in the disguise of 
"interdisciplinary approaches" and with reference to some alleged requirements of legal practice.

\section{SOCIOLOGY FOR LAWYERS AND SOCIOLEGAL RESEARCH}

The experiences derived from a specific sociological course in the legal education environment may serve here as an illustration of the legal studies approach suggested here. Sociology is taught to law students in the framework of the course Sociological Jurisprudence at the Faculty of Law of the University of Sydney. This course is offered by the Department of Jurisprudence as a specialised course. ${ }^{8}$ This means, that the course may or may not be the only course in the curriculum of the law faculty where sociological or sociolegal knowledge is used and applied, but it is the only course in which the sociological approach itself rather than the substantial results which it may or may not produce is made the subject of the course. This course makes theory construction and research methodology its primary concern; it does not assume that methodological skills and theory consciousness are the inevitable by-products of legal education whenever substantive rules and procedures of constitutional law, company law, criminal law and so on, are taught. In "problematising" how human knowledge in general and scientific and legal knowledge in particular are produced and socially reproduced, the course specialises legal knowledge further.

Such a methodological self-consciousness is, of course, at the core of scientific knowledge production at large. The purpose of the scientific organisation of knowledge is to observe accountably how scientists and others make their observations and to hold this process of observation open for making further observations. Legal education can generally avoid such a scrupulous, intentional indeterminacy in its reproduction of knowledge because the objective of legal education is the communication about practical knowledge ("Tell me, how would you decide") and to close the operation of such knowledge normatively ("Tell me, on what (dogmatically accepted) reasons do you base your decision(s) and how do you justify (rationalise) it/them”). As a result, the theory of legal practice as communicated through legal education is an 
eclectic arrangement of operatively closed (dogmatic) concepts. Here the sociology course can re-introduce indeterminacy of knowledge and problematise both scientific and legal knowledge production. It can demonstrate how the production of knowledge is primarily a social process and exclusively socially determined, ${ }^{9}$ and that we only know what we think is worth knowing. It could even be said that lecturers who teach sociology in law schools have an obligation to make law students see the connections between the social construction of knowledge and the reproduction of legal knowledge, to make the invisible factors behind both the operation of law and the learning of the operation of law more visible. In this sense, the function of a sociological course in the legal education environment is not that of a course in sociology of law but that of a course in sociology for lawyers. It seems that only in this framework sociological knowledge and sociolegal research can assume a practical meaning for law students.

The overall objective of this course is to introduce the law student to social science research which is guided by theory. This is attempted by presenting, in the first part of the course, sociology and sociological concepts with one consistent theory design ${ }^{10}$ and by relating the historical plurality of sociological theories and concepts consistently to this theory design. ${ }^{11}$ The rationale for this approach is:

a the insularity of the only sociology course - 52 hours (one semester) in a law degree programme - and the rather dramatic difference in the subject matter of sociology as compared to law subjects in general would leave a dogmatic presentation of a wide variety of sociological and sociolegal material without much impact.

b The maxim that learning to handle sociological theory is an active rather than a receptive process demands that law students should be empowered to begin as early as possible to work with sociological theory in order to develop their own practice of theory construction. The theory consistency in the introduction of sociological concepts can be seen to speed up the attainment of competence in sociological work under the given circumstances of the legal education environment. In the second part of the course, social science research methods are introduced and discussed. In view of the plurality of 
research strategies and of the highly specialised varieties of social science research methods, the discussion of methodological approaches concentrates on one particular approach (qualitative/ interpretive/ ethnographic approach) as an example. The reasons for doing are similar to the ones above:

c The maxim of the unity of theory construction and methodically controlled research demands that students are given the opportunity to learn through practice to understand that the one cannot be operated without the other and that the design of the one is contingent on the design of the other.

d The time frame of the course, makes a selection necessary. Given that comprehensive instruction in all major social science research approaches is not feasible and that the dogmatic pretence of a free choice between several research strategies belies the reality of social science research, the ethnographic approach has some tangible advantages over other research strategies.

e Ethnographic studies keep the demand for highly specialised, statistical-mathematical technology and know-how for data collecting, processing and evaluation at a low level. Apart from the fact that most law students have no previous experience with statistical methods and computer based research, ${ }^{12}$ the organisational facilities and academic culture of a law school are rarely conducive to large-scale, quantitative social science research.

f Ethnographic studies provide arguably the most crucial methodological key to the observation of "society in action" because they leave the ensemble of context, processes and outcomes intact during observation, rather than violating this context by the predesign of structured research tools for the extraction and aggregation of quantitative data in the computer laboratory (for instance in quasi-experiments) or irrespective of that context (for instance in surveys).

g Ethnographic studies allow every law student to interact individually with the social environment in which observations are made and to gain primary, and in this sense meaningful, experiences in the field. This experience would be rather restricted and less meaningful if it was left to the 
more technical aspects of dealing with quantitative data.

$\mathrm{h}$ On a wider basis, ethnographic studies can be seen as a scientific design to counter the - largely economy induced - overreliance on short-term, measurable and quantifiable information in the construction of knowledge while underrating the social context and long-term processes with the social construction of knowledge as their outcome but which is difficult to measure.

In summary then, in a situation in which a certain compacting of the introduction to sociological research is necessary so that students quickly develop competence for undertaking their own research, with respect to both theory-construction and the conducting of methodologically controlled observations, it is not only a possible but a meaningful choice to include a practical ethnographic exercise in the programme of a course in sociology for lawyers.

\section{The Organisation of an Ethnographic Study in the Legal Education Environment}

The historically and culturally determined limitations of legal education are well known. ${ }^{13}$ The dogmatic emulation of legal practice gears students to rote learning and to cramming for examinations rather than to prepare them for participatory selflearning. It produces the typical profile of the performance of the law student population as the result of their socialisation responses under educational arrangements which are, in this specific form, hard to find in any other field of tertiary education. Students are primarily disinterested in the content of and only instrumentally involved in their studies. This means that studying law is rarely experienced as intrinsically rewarding other than by leading to a useful degree; law students rarely find lectures to be a stimulating experience and they do not come to lectures when they can avoid doing so; they take down and trade lecture notes rather than to annotate and selectively evaluate lectures themselves; they rely in their studies more on textbooks than on research literature, especially from other, non-legal disciplines, ${ }^{14}$ and they are more concerned with the legal-professional status of the person who said something than with what was said; they give their limited attention preferably to subjects the utility value of which is established by 
high examination pressure, and so on. These socialised routines, rather than educationally intended learning behaviours, may be effective to pass successfully through law school but they act clearly as obstacles for the participation in a sociology course in a legal education environment. In some respects these obstacles can be reduced by organisation and preparation, for instance by a more central and frequent use of teaching aids (projection of visuals for graphs, organisation charts, or simple lists, etc.) and a meticulous timing of each step of the introduction and discussion of new material. This applies particularly to the research work undertaken by the students themselves which needs a longer lead time, depending on the objective of the study and the class size. If, for instance - as in our example below - the fieldwork of 70 students has to be coordinated and conducted within the narrow timeframe of two months and the peculiar hydrocephalic demographic structure of an Australian state and, above all, without "burning the field" which - apart from all ethical considerations - may be the research environment for many sociolegal researchers and law students to come,${ }^{15}$ early thought must be given to the research area for and the nature of the fieldwork.

However, in some respects the participation of law students is enhanced in a sociology course through its research orientation. While the amount of work and the investment of expertise which are necessary to conduct such a course are considerable, they not only pay off best but practically are only possible if the teacher is involved in sociolegal research and can utilise the lectures for the development of ideas and concepts for theory-construction and research design by discussing them with students but also by doing fieldwork according to such concepts together with the students or independently from their work. In this sense, a course of this type can be seen as the useful extension of sociolegal research, especially as a pilot study or in its explorative stages. The material interest of the lecturer in the results of the didactical process can lead to a more consistent design of the course, and above all to a more meaningful involvement of the students in it: here research is not seen as a simulated exercise but as a meaningful piece of collective work which connects with "real life" and the processes of scientific knowledge production. 
Table 1: The Day in Court

\begin{tabular}{|c|c|}
\hline \multicolumn{2}{|c|}{ COURT ENVIRONMENT } \\
\hline 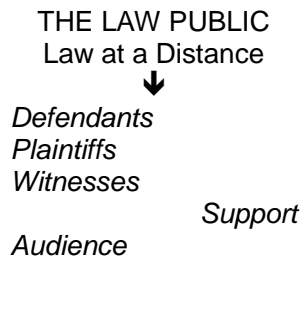 & 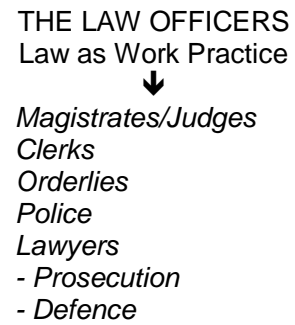 \\
\hline
\end{tabular}

\section{Design and Execution of Research versus Assessment of Student Performance}

Under the given restrictions, where didactical efforts may conflict with research efforts, projects can only be very narrowly defined and can attempt, in sample size and quality, only a limited representativity. However, also here an ethnographic approach has advantages. In its explorative thrust, this approach does not aim at the representativity of a given sample but at the validity of the observation of given contexts, processes and outcomes. This allows the student to focus on the case in hand rather than on attempts to accumulate a great number of cases, often in a rather superficial and wasteful manner. In this respect, projects in two previous years which had been directed by more stringent sampling requirements for the collection of quantitative data proved to be less satisfactory under the didactic aspect. The structured nature of the research tools (interview with partly structured questionnaire) in order to obtain quantitative data, and the lengthy statistical analysis and evaluation of the data prevented wider participation by the students in the project over its full duration. The evidence from this experience supports the position that it is more desirable for students to design and conduct their own studies during the course and under supervision rather than practice established research routines, and that they also are given the opportunity to evaluate their studies and report their major findings, as far as this can be pressed into the extremely short time span of a semester (14 
weeks). Obviously, striking a balance between meaningful learning and fruitful research can only be approximated by continuous experimentation.

One factor which may upset this balancing in the legal education environment is the all-deciding requirement of student performance assessment. This has the distracting consequence that the research activities of individual students and their results have to be designed in such a way as to be examinable on an equal footing. In other words, the performance of students needs to be assessed uniformly where they, in fact, may possibly perform quite heterogeneous tasks ${ }^{16}$ and performance requirements need to be policed. On the other hand, closer scrutiny of student performance could be seen enhancing the quality of research in all stages, including a closer observation of interviewer behaviour. Finally, assessment of research and research operations can assure students that, by conducting demonstrably their own research, their own and independent contributions count rather more than the reproduction of the wisdom of others lifted from notes and casebooks.

In balancing the advantages and disadvantages of the requirement of performance assessment, thorough consideration must be given to form and to the fact that assessment is of crucial importance for a high actual participation rate. ${ }^{17}$ In the framework of highly instrumental student behaviour such as in a law school, the form of assessment interacts rather directly with actual student involvement (attending lectures, attention, strategic advantages of given choices and so on. The resulting student performance, however measured, is a consequence of how well the form of assessment manages to reflect the teaching-learning objectives in terms which are relevant and meaningful for the student. With the on-going complex change of how law students construct what is relevant for them, ${ }^{18}$ only continuous experimentation can provide answers. Our three projects ranged from a mix of a compulsory essay (for the theoretical part of the course), an optional research assignment (with 90\% participation) and an open book examination (designed for policing participation) ${ }^{19}$ to a compulsory essay and a compulsory assignment in lieu of the examination. ${ }^{20}$ Over the same period, assessment of the research assignment varied from an assessment of the quality of methodological procedure requirements (with respect to initially structured but subsequently 
partly unstructured interviews) ${ }^{21}$ to an assessment of the quality of methodological procedure and of the findings obtained with the applied approach (see chart 1). In the first exercises of this kind, control of the identity of the presented research work was obtained at first through a personal interview of the lecturer with each student about their work. This was later replaced by the current combination of, on the one hand, the mandatory requirement of providing transcripts obtained from audiotaped interviews and, on the other hand, a social control component in form of collective student work, ${ }^{23}$ Experience with this variety of assessment procedures showed, in sum, that the move towards dropping the compulsory examination and making the research assignment compulsory instead, reduced attendance in class but increased the quality of both theoretical essays and the research work in terms of their originality and the expression of well-reasoned opinions. This seems to support the proposition that in the legal education environment students respond well to the offer of having selfinduced work rewarded rather than conformity. The experience also suggests that they differentiate succinctly between the liberty to provide for the assessment of, as one student put it, "true expressions of opinion based on research and the subtle pressure in other law subjects to reproduce faithfully and somewhat mechanically what has been presented to them in class.

\section{THE DAY IN COURT — AN ETHNOGRAPHIC STUDY}

The above experiences and considerations suggest that research work in a sociology course for lawyers should preferably be a pilot study rather than constitute part of an already established study in which students perform only some research functions. An ethnographic study of local courts qualifies as a didactical pilot study in many respects. Even though there is a considerable amount of research literature on the operation of courts, comparatively little of that research is devoted to the study of local courts. The bias towards research predominantly of the appellate and higher courts underlines the fact that research on courts is conducted generally under the guidance of a social control concept which is provided by legal doctrine and by an internal view of legal system operation. This doctrinal perspective posits that courts are a rationally used instrument to effect social control and that the higher the courts are, 
the clearer (better "measurable") the effects of the operation of courts are seen to eventuate. This perspective posits further that the normative decisions by courts have a direct, even if unclear, effect on social life and that these effects correlate positively with the operation of higher selectivity in the legal system, as reflected by the differentiation of courts and in legal practice. In other words, legal decisions are the more effective the higher the court is which issued the decision. Law students internalise this legal theory of the operation of courts by studying almost exclusively cases and decisions from courts of superior jurisdictions. Local courts are almost non-existent on that normative map.

A sociological perspective on how law operates, suggests almost the opposite. While there is no question that legal systems become more stable by a selectively controlled purification of internally produced decisions at higher levels (stabilisation of precedents and doctrine, appeals, "hard cases" and so on), it is by no means clear that the higher level law also means more effective law. From a sociological view, law appears to operate as one and same law on all levels; legal systems operate, as a whole, the same highly differentiated structure of legal (internal) communication about what is law and what is not in order to arrive at legal decisions of any type. This communication includes the message that the work of the superior jurisdiction is concerned with referring law events (cases) to law in a small number of cases, while the work of local courts is concerned with referring "notlaw" events or "not-yet law" events to law in a great number of cases. From this perspective, the operation of local courts can be seen as the crucial border patrol where legal systems enact selectively their reproductive everyday interchanges with society at large and where this is experienced as law.

Also the Australian research literature on courts, as far as it can be found, examines the operations of courts predominantly under the perspective of the social control paradigm. The central question here is how measurably efficient courts are in their administrative operation, or in other words, how fast their case load is turned over, with the assumption that this administrative efficiency is somehow related to and produce something like "order" or "justice" in society. ${ }^{23}$ Instead, the objective of the pilot study conducted by the students in 1989 was to examine whether such assumptions of the 
connection between organisational efficiency and effective social control effective hold and how the administrative operation of local courts is actually experienced by officials and the public as the operation of law. In order to proceed with this analysis, the social control concept was contrasted with a concept which sees the operation of local courts as a design for the operative closure of legal decision making which, first of all, is necessary for the reproduction of the legal system. In order to test this concept, the research design of an ethnographic study was used to canvass the context, processes and outcomes occurring at the day in court in their entirety of social organisation rather than as discrete occurrences at the will of individuals.

\section{Theory Design}

The approach of the theory of social systems suggests that the social control concept can only describe the normatively desirable or perceived goal of social control but not the actual operation of courts. The actual operation of (local) courts is the result of a complex, on-going aggregation of communicative events which constitute communicative processes. Stabilised communication and nothing else, in turn, constitutes social systems. ${ }^{24}$ Conversely, social systems, and (local) courts among them, need on-going communication for their continued existence. Local courts provide the legal system with an unceasing communication about law through their exchange with the public expressing what is lawful in everyday life and with respect to everyday life situations. In this sense, local courts constitute the "life-line" for the operation of legal systems: they feed, by handling a massive caseload in their daily selective operation, a continuous stream of such communications to the legal system as a whole.

On the other hand, the operation of local courts shows also the problematic nature of the selective handling of communication with the legal system and about law. The prime function of courts is to sequester and produce further legal references. In a strict sense, therefore, courts do not offer solutions for the everyday situations about which courts communicate with the public but they produce only answers for the legal system which confers here with itself and reproduces law as a result. Overall, the public have difficulties to see the concrete effects or successes of court action, but they can 
feel very well the repressive power of law, its diffuse authority and the shadow of coercion. The public rejects, accepts or even seeks legal references for their own further use in organising everyday life mainly because of that diffuse authority of the law. On the other hand, this diffuse authority distracts attention from the fact that courts deal with the law and not with people, and that they have no control over whether or not legal communication is in fact accepted by the public. This is even so when courts use force, which may hurt people economically, psychologically or physically. Yet punishment is not related to how and why people act in the way they do but is only relevant to the consistency of legal operation. In this context of the separation of the levels on which, on the one hand, the legal system and the courts operate and, on the other hand, other social systems and people operate, the legal solution may become, but need not become, a "real life" solution for the case in hand and for the parties concerned. However, it provides the legal system in every instance with the essential communicative events which it needs for its reproduction. And while local courts bravely stem the tide of "sausage factory" workloads allegedly to the detriment of the individual case, it is, paradoxically, precisely the intensity and high frequency of the turnover of caseload in the local courts which characterises the essential quality of a legal system.

In our ethnographic approach, the unity of a local court appears as a scene on which the on-going communication can be expected to be necessarily biased toward feeding the legal system with communicative events. Accordingly, the public contribute their own stories - more or less reluctantly — only to some measured degree and not without heavy-handed selection (see table 1). The law officials are involved in producing legal communication, and they benefit from producing such a privileged communication in different degrees. ${ }^{25}$ They experience the reproduction of law as their work practices. The public, that is, those lay persons who come to court are exposed to or expose themselves to that privileged communication and they accept the outcomes of this communication in varying degrees. They experience the reproduction of law as a distanced happening with mythopoetical effects. The instances of concrete interaction and the crosscommunication between these two different spheres of court action 
are comparatively rare and are highly controlled through legal procedure and legal-professional work practices. However, for the legal system to succeed in reproducing law, officials and public must be seen to communicate with each other. This is what having one's day in court is all about. We can, therefore, assume that the main function of local courts is to facilitate that kind of communication which the law officers and the public need in order to proceed with communicating about the law in the way they do.

The objective of the study was to determine, through empirical research, the structure and the operation of this communication in local courts and in what way it is related both to the operation of law in society at large and to the social need of individuals, agencies or organisations for what they see to be "their" day in court.

\section{Methodological Design and Execution}

In the methodological design of the study, the didactical requirements of the law degree course and the research requirements of empirical research intersect. Whenever the two conflicted, primary consideration was given to the didactic objectives of the course. To begin with, the feasibility of the project was addressed by contacting the administration of justice in Sydney on two levels. On the local level, contacts were made with a selected Clerk of the Court who was invited to address the students in a lecture, in which the practical work of local courts was described and discussed. On a higher level, letters were written to the Attorney General, the Chief Magistrate and the Chief Justice of the Land and Environment Court respectively which set out the objectives of the study and asked for permission to conduct the exercise with students. Permission was granted in each case; although, in the case of the Land and Environment Court only after a consultation with the Chief Justice.

The descriptive presentation and discussion in the lecture given by the Clerk of Court provided the basic information for the actual operation of the courts. ${ }^{26}$ From this base, items for the interviewguide were selected which consisted of 17 unstructured (openended) questions which to both the public and the officers were to be addressed. ${ }^{27}$ The function of the interview was to solicit from the respondents their references to the concepts of law, the operation of 
law, the justice or fairness of the law, their observations of the actual operation of the court, of the court as a work environment, the atmosphere of the court, and so on. This interview-guide was designed in class and it was decided that both the public and officers should be asked the same questions, as far as was practical and meaningful. ${ }^{28}$ It was further decided, that, with respect to the pressure from the court environment on the respondents and the requirement of a full length transcription of the recorded interviews, the length of the interview should not exceed approximately 30 minutes. ${ }^{29}$

Further, the expert interview with the Clerk provided also a list of a mix of 13 suitable $^{30}$ criminal, central city and suburban courts and some special courts on the first instance level (children's/family court, Commonwealth court, Land and Environment Court) in Sydney. We contacted the Clerks of all courts and asked for their permission to conduct the interviews on their premises. At this stage three Clerks felt that the workload and/or size of their courts would not allow participation by their staff in the exercise and declined co-operation. With 10 courts remaining, 10 teams with 7 students were formed. Students were allowed to select freely a court with the result that final teams were not made up equally of 7 students in all teams.

With the research teams formed, the task of the student was (see table 2):

Table 2: The Day in Court

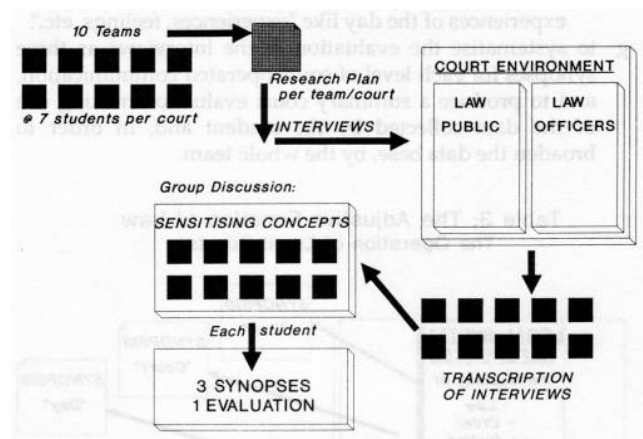

a collectively to design a research plan of the person to be interviewed at their assigned court and to submit the plan to the Clerk of the court for his or her approval;

b to conduct two interviews, one of which was to be conducted 
with a member of the public and one -with a law officer (for list of respondents see table 1); -

c to keep a log book on the field-work and include additional observational data abut the preparation, setting . . and execution of interviews;

d to produce a transcript of each interview;

e collectively to establish in group discussions recurring patterns of references or concepts most frequently used by the respondents ("sensitising concepts") in the interviews conducted by the team members;

f to evaluate individually the student's own (two) Interviews in the light of the group discussion and with respect to the established sensitising concepts, having special regard to three levels of the operation of communication in courts (see table 3):

i the level of the operation of 1-1 system references such as "law, order, justice, public interest", etc.

ii the level of the operation of court organisation references like references to work practices, court officials, work loads, administrative designs and routine schemes and so on;

iii the level of intrapersonal references related to the experiences of the day like "experiences, feelings, etc."

$\mathrm{g}$ to systematise the evaluation of the interviews as three synopses for each level of court-operated communication, and to produce a summary court evaluation making use of the data collected by the student and, in order to broaden the data base, by the whole team. 


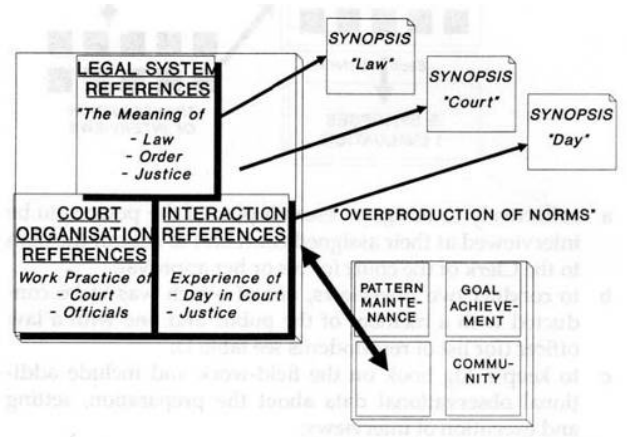

The assessment of student performance was based on the quality of the execution of these tasks and the transcripts, logs, synopses and general court evaluation provided the documentation for such an assessment (see table 4). Students were particularly instructed to observe the ethical demands on social science researchers not to exert any pressure on the potential respondents to give or to proceed with an interview and to begin every interview with the assurance given to the respondent that the interview was voluntary, that the respondent was free to abandon it at his/her will, that no names or identifications would be recorded and that all information gathered would be treated confidentially.

The alternation of collective and individual work sequences in the design of the exercise was expected to lead to a better basis for the research experience of the student. It was supposed to offer a further level for the discussion and reflection on research results which, due to the restraints of the type of research conducted here, would appear to the individual student highly contingent and unrelated to the larger context of the court operation. It was also expected that the collective work should provide for a better participation and exercise a degree of social control over the work of the students among themselves, such as preventing faked interviews. $^{31}$ 
Table 4: Assignment Requirements

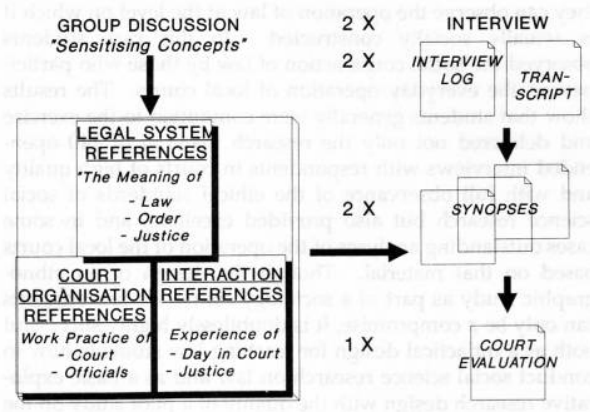

\section{CONCLUSION}

The objective of qualitative research is to avoid the early operative closure of the research approach. This means, that, rather than using a prefabricated grid of concepts which is the result of scientific operations following the rationale of scientific discovery (formulating and testing of hypotheses through analytica1 statistical measuring designs) and which extracts from the units under research only those references which make scientific sense to the researchers themselves, ${ }^{32}$ the interpretive researcher attempts to tap with his or her observations the use of the concepts (references) which are used by the participants themselves ${ }^{33}$ and which help them to communicate in everyday life. In evaluating the use of these references, the researcher can attempt to reconstruct social processes as a concatenation of the use of such references (communication) which constitutes the social reality of the respondents and which directs their actions.

The practical use of such a research approach can constitute a substantial learning experience for law students where they are put into the position of the researcher and where they can observe the operation of law at the level on which it is actually socially constructed. In this case students observed the social construction of law by those who participate in the everyday operation of local courts. The results show that students generally were committed to the exercise and delivered not only the research material of 140 open-ended interviews with respondents in courts of high quality and with full observance of the ethical standards of social science research but also provided excellent, and in some cases outstanding analyses of the operation of the local courts based on that material. 
Though the design of an ethnographic study as part of a sociology course for law students can only be a compromise, it is doubtlessly highly successful both as a didactical design for teaching law students how to conduct social science research on law and as a basic explorative research design with the quality of a pilot study on the operation of local courts.

The most problematic part of the design overall was the assumption that students would appreciate collective research work and that they would be able to use group discussions and group work to their benefit. These results show that students partly did not fully understand the objectives of the group work or did not see the necessity for devoting time to group discussions, often cooperated only reluctantly in a team and a few not at all. Clearly, this collective element should either — time permitting — be strengthened organisationally, for instance, by explaining in more detail the objectives of the group work and by including timetabled group sessions in the programme of the course in order to monitor the progress of group work. Alternatively, it should be dropped altogether notwithstanding the social control function of group discussions.

However, even given the poor cooperation of a few students, the reliability and the quality of the data and the observational and evaluative skills of law students are extremely high. The collected material is a rich and fertile ground for further and more controlled ethnographic studies on local courts and on court operation in general. Above all, however, the exercise has a stimulating and eye-opening effect for many law students, some of whom though in the last years of their law studies - not only set foot for the first time into a local court but also felt, for the first time, that they were beginning to understand what law is all about.

* Department of Jursiprudence, University of Sydney.

(C) 1990. (1990) 2 Legal Educ Rev 59.

1 E Ehrlich, Freie Rechtsfindung und freie Rechtswissenschaft (Free legal decision-making and free legal science) (Leipzig: reprint Aalen, 1973) 196; partly translated as, Judicial Freedom of Decision: Its Principles and Objects, in (1917) 9 Science of Legal Method, The Modern Legal Philosophy Series 47.

2 Id.

3 KA Ziegert, The Sociology behind Eugen Ehrlich's Sociology of Law (1979) 7 Int'l J Soc L 225.

4 KA Ziegert, Legal Education at Work: the Impossible Task of Teaching Law (1988) 3/4 Tidskrift für Rättssocwlogi (No 5) 183-211; KA Ziegert, Lifeworld and Legal Impact in Australia and Sweden: the Diffuse Law Concept, paper 
presented at the Australian Law and Society Conference, Melbourne, 12-14 December 1989.

5 Ziegert, Legal Education at Work, supra note 4.

$6 \quad$ KA Zeigert, Dogma im Zeichen des dicken Hunds. Die Rechtssoziologielehre in der Juristenausbildung (The hypertrophied dogma. Teaching sociology of law in the framework of legal education), in R Voigt \& A Gorlitz eds, Iahresschrift fiir Rechtspolitik, Vol. 3 (Paffenhofen: Centaurus, 1989) 220-254.

7 This goes to such lengths as constructing moot competitions as the pinnacle of law school performance although perhaps this is typical only in societies with a cultural background for the rhetorical quality of law, that is, in common law or Anglo-American legal culture.

8 This label for the course has mainly historical reasons, because the course is one strand out of five which constitute the (compulsory) subject "Jurisprudence". Each law student must at least complete one jurisprudence course for the law degree, but students can do more than one strand an elective subjects.

9 I appreciate that this statement can be seen and understood as an imperialist argument and 1 do not dispute that there are many more aspects involved in the construction of knowledge than only the sociological one, ranging from biological sensory equipments to political discourse. However, these other aspects cannot detract from the fact that all individual consciousness and learning determined by social interaction and communication and that the issue of intersubjective (social) exchange is the pivotal one in the reproduction, that is, ultimately social construction of human nature.

10 While this is not unusual for sociologist training, it is in sharp contrast to the highly eclectic approaches to teaching and learning in legal education, particularly in its jurisprudential fringes.

11 This leads to a working knowledge of the theory of social systems and includes a brief outline of the history of sociological ideas, especially with respect to law. The design of the theory of social systems ("operatively closed systems") is as far as I can see - the most advanced development of sociological theory and at present without viable alternative but it does not claim exclusivity. The educational advantage of the theory design is that it enables the student to observe social process on the micro-social (intra- and interpersonal) levels and on the macro-social (intra- and intersocietal) levels with one and the same theoretical approach. It also links the social science aspects of human existence with psychological and natural science aspects.

12 This is so even when all students, in fact, combine their studies toward the law degree with studies toward another degree (in arts, economics or science). Though students individually may have had the advantage of exposure to research methodology in these other studies, especially in economics, history, government, anthropology and sciences, it remains a difficult task for these students to relate the relevance of this experience to sociolegal research. This situation is compounded by the fact that, as far as the University of Sydney is concerned, no degree in sociology is offered. As with so much else in legal education, it is unclear what the studies toward a combined law degree actually achieve other than the improved marketability of the degree or accumulation of cultural capital. Ziegert, Legal Education at Work, supra note 4.

14 This tendency is reinforced by the highly specific meaning of "research" to which law students are introduced in their first semester studying law. Legal research here means locating law texts (textbooks, cases, statutes, references to cases and statutes, etc.) and is internalised as this locating of texts rather than as the logic of scientific discovery.

15 Though, in a strict sense, no researcher leaves the field in the same state as he or she found it, thoughtful planning of how to enter, work and leave the fields of ethnographic study can contain the worst damage and can make research a 
fruitful experience not only for the researcher but also for those professionals, officials and respondents in the general public who sacrifice their time for the research.

16 For instance, circumstances of interaction with respondents in the field can vary greatly and are beyond the control of most, but especially the inexperienced researchers. Also even if, for instance, respondents cooperated only reluctantly or not at all, the interview produced valid data (and would not have to be substituted by another interview). However, such a meagre output appeared to many students to be less "good" than if the respondent had talked a lot which would have yielded a longer transcript with a fuller scope of references for interpretation and evaluation.

17 This means actual, self-referential involvement of the student by interest and not just nominally performing the task in one or other form. On the other hand, an over-emphasis on linking student performance with the research assignment, for instance by weighting it as the most important of all components for assessment in the course, would inevitably also increase other "deviant" forms of participation, i.e., faking, cheating, paying others for doing the work etc. which would be equally difficult to police.

18 The mapping of these relevant and meaningful environments by law students can be seen as the actual socialisation effect of legal education. Compare KA Ziegert, The Social Construction of the Legal Mind: A Study of Law Students and the Accumulation of Cultural Capital (Sydney: Oxford University Press, forthcoming 1990).

19 In this mix the essay and the (optional) research assignment counted for 25\% each while the examination counted for $50 \%$ of the total mark for performance in the course.

20 In this mix the essay and the research assignment counted for $50 \%$ each of the total mark.

21 With respect to the care and meticulousness with which interviews had been prepared, executed and documented.

22 The requirement of the collective groupwork component appeared to present the greatest difficulty in this project and a large number of students resented the idea of having their own achievements made contingent on the achievements of other students. In spite of the fact that great care was taken to explain the structure and function of the group work to the students, a considerable number did not understand or plainly circumvented the group work requirement. It appears that the reference of students to traditional assessment procedures with their highly individualising and competitive implications interfered here most massively as far as the quality of research is concerned.

23 C Briese, Future Directions on Local Courts in NSW (1987) 10 UNSWLJ 127; J Newton, The Magistrates Court 1975 and Beyond (Canberra: Institute for Criminology, 1975).

24 For a more detailed exposition of this approach see Ziegert, Lifeworld and Legal Impact, supra note 4.

This does not ignore that there is clearly a further differentiation of both the public and officers (compare table 1) which often is experienced but also constructed as more important (for example, between adversary parties, between clerks and magistrates/judges, between court officers and lawyers, etc.) than the fundamental division between legal and nonlegal communication and the study can, in fact, trace all those further differentiations for further interpretation of their functions.

26 As opposed to the information which students already had about the operation of local courts from legal research, basically only in the introductory course on legal institutions.

27 The interview guide contained also 10 demographic questions which were to be asked, at the end of the interview at the discretion of the interviewer/researcher. 
28 Practically and in order to avoid embarrassment, the wording of some questions had to be modified depending whether a layperson or a law officer was addressed, and these modified questions for the one or other group were clustered through filters in the interview guide-line.

29 As a result, interviews with the law public lasted on average shorter than 30 minutes and interviews with the law officers on average a little longer than 30 minutes.

30 Suitability was assessed by the size of the court and whether or not it was big enough to allow a group of about $5-10$ students to conduct a sufficient number of interviews with a sufficient variety of respondents without disturbing the field, for instance, by conducting two or more interviews with the same member of the court staff.

31 Though it is difficult to speak with full confidence with respect to the actions of 80 researchers, the only "deviance" which came to notice was a substitution of respondents In variance with the research plan for a specific court in a few cases.

32 For instance, by submitting a question of the type: "Here is a list of the functions of the law a) to d). Please tick the function(s) of law which you consider to be the most important!"

33 For instance, by submitting the question "How would you describe what law is?” 